\title{
Seabed substrate, water depth and zooplankton as determinants of the prespawning spatial aggregation of North Atlantic herring
}

\author{
Christos D. Maravelias"1, David G. Reid ${ }^{1}$, Gordon Swartzman ${ }^{2}$ \\ 'FRS Marine Laboratory, PO Box 101, Victoria Road, Aberdeen AB11 9DB, Scotland, UK \\ ${ }^{2}$ Applied Physics Laboratory HN-10, University of Washington, Seattle, Washington 98105, USA
}

\begin{abstract}
The distribution of a pelagic species, the North Sea herring Clupea harengus L., derived from acoustic surveys during the summer and prior to spawning is shown to have a strong relationship to seabed substrate and water depth. Substrate information was derived from a remote acoustic classification technique (RoxAnn). Herring were shown to aggregate in areas characterised by a seabed of sand and gravel. This type of substrate is similar to that on which they spawn, yet the surveys were carried out 2 to 3 mo prior to spawning. The herring also showed a preference for zooplankton-rich waters with depths between approximately 100 and $150 \mathrm{~m}$. These relationships were examined during 3 years (1992, 1994, 1995) using Generalized Additive Models (GAMs) and were found to be stable between the years examined. Results indicate a robust relationship between spatial distribution patterns and these environmental factors, despite substantial changes in the stock level and age structure of the population. A multiyear GAM analysis confirmed the stability of this relationship and the stock's reduction. Herring preferences for specific substrate types, water depth zones and zooplankton conditions are hypothesized to modulate the prespawning spatial aggregation of the species to potentially suitable spawning grounds.
\end{abstract}

KEY WORDS: Generalized Additive Models (GAM) - Acoustics - Seabed - Substrate - Pelagic - Depth . Zooplankton - Herring $\cdot$ Distribution - RoxAnn

\section{INTRODUCTION}

Relationships between fish distribution and environmental variables have attracted growing research attention in recent years. In general, the environmental aspects studied are restricted to physical oceanographic parameters such as temperature and salinity. The distribution of pelagic fish is, however, a complex phenomenon controlled by a number of interacting mechanisms and factors. One factor which Mann (1993) highlighted was zooplankton abundance and hence food availability. Another factor which has received little attention, particularly for pelagic fish, is the relationship to seabed structure.

\footnotetext{
- Present address: National Center for Marine Research, Agios Kosmas, 16604 Hellinikon, Athens, Greece.

E-mail: cmaravel@ncmr.gr
}

The North Sea herring Clupea harengus L. is a pelagic schooling species that makes regular seasonal migrations as part of its spawning and feeding cycle. Herring is the only marine clupeoid which lays demersal eggs. Eggs are laid on gravel areas on the seabed (Blaxter 1990). In the North Sea, herring are considered to be conservative with respect to their spawning grounds which are usually located in high-energy environments (Blaxter \& Holliday 1963).

Herring are believed to contract their feeding and spawning range as the population declines (Murphy 1977). Thus at high stock levels, eggs are spawned in highly variable and generally less productive offshore areas as well as in the more consistently productive inshore zone (Blaxter \& Hunter 1982). North Sea herring start feeding in April in areas with high abundance of Calanus finmarchicus or euphausiids. C. finmarchicus is the principal food of herring. Within the North Sea, 
pioneer work on herring-plankton relationships was done by Hardy (1936), who showed a negative relation between herring and dense phytoplankton blooms and a positive relation between herring and their food organisms, particularly C. finmarchicus. Cushing (1955) studied in depth the herring-zooplankton relationship by examining the population dynamics of a patch of $C$. finmarchicus, relating it to the primary production $c y-$ cle and the aggregation and disengagement of herring from the patch. Herring feeding continues until July, when the fish stop feeding and start aggregating in pre-spawning schools. These schools gradually move in the direction of the various spawning grounds near the Shetland/Orkney Islands (Fig. 1).

There is considerable evidence that herring distribution is related to zooplankton distribution. Bainbridge \& Forsyth (1972) related the 1960 s northern displacement of herring spawning grounds to large scale changes in composition and abundance of the zooplankton in northwestern North Sea. Corten (1988) proposed that the observed southerly shift in herring spawning grounds from Orkney-Shetland to the Buchan area in the 1980s was a reversal of the trend that

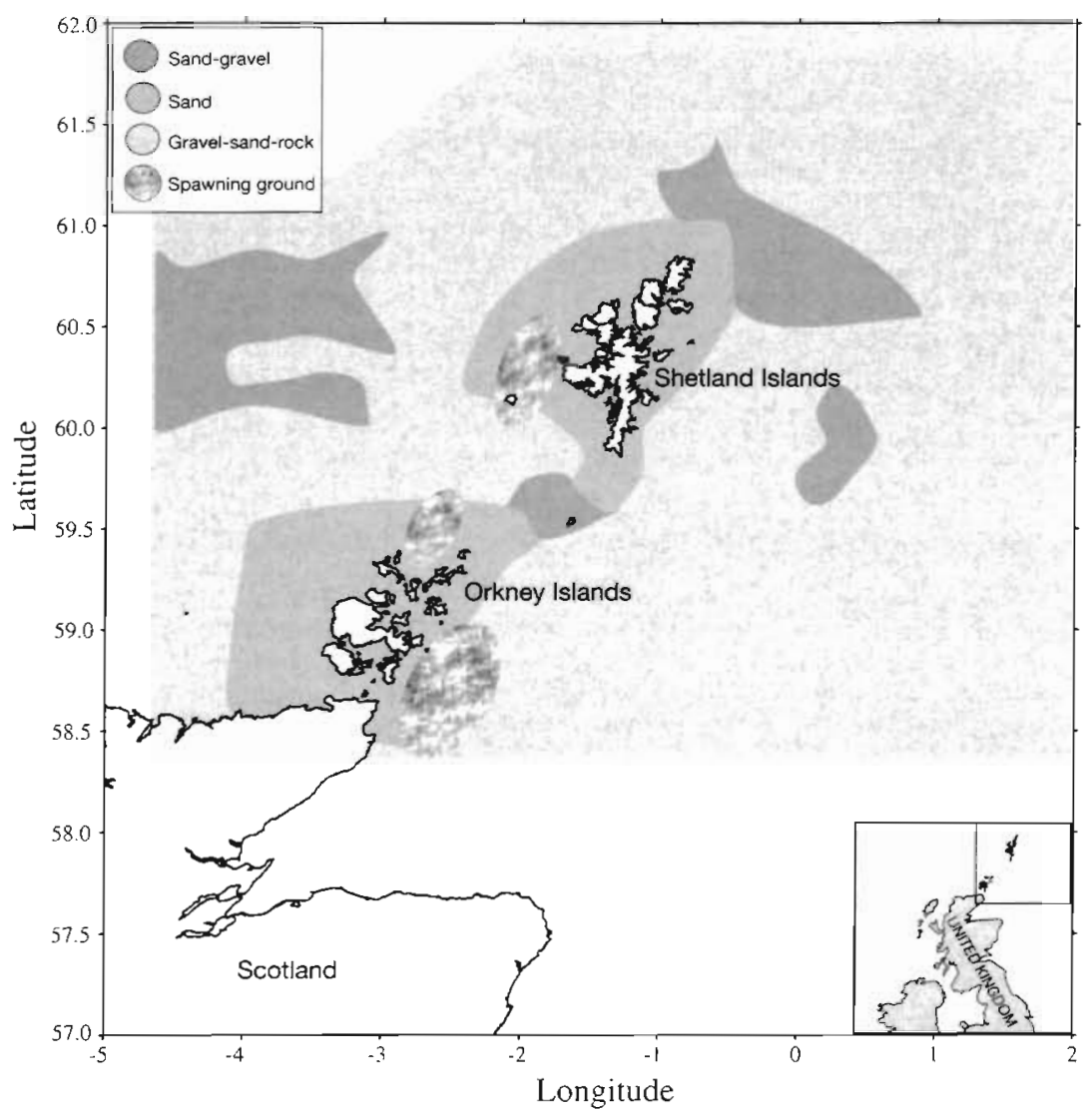

Fig. 1 Herring spawning grounds (redrawn from Corten 1990) and seabed sediment derived from the United Kingdom Digital Marine Atlas (UKDMAP) database was observed in the 1960 s. By the late 1980 s the herring again showed a more northerly distribution pattern of spawning. The distribution of herring catches in June/July during the late years of the 1980 s was concentrated in the region of the Slope Current (Corten \& van de Kamp 1992). Corten \& van de Kamp speculated that changes in the Slope Current might have been responsible for the changes in the summer distribution of adult herring in the 1980s in the northern North Sea. Haegele \& Schweigert (1985) had proposed that herring migrate from offshore feeding grounds to near shore holding areas close to spawning grounds, one to several months in advance of spawning and then disperse to the ultimate spawning location a few days to a few weeks prior to spawning.

North Sea herring stock had undergone significant fluctuations in the early 1990s. During the period that the present study examined, 1992 to 1995, the stock underwent a number of changes in response to a combination of variation in recruitment and heavy fishing pressure (ICES 1997). Recruitment had failed to maintain the high levels of the mid to late 1980s although there was no recruitment failure. Fishing pressure increased dramatically from 1992 for 4 yr, with fishing mortalities up to 0.8. As a result, the stock reached a low point in 1997 but is now recovering. Under this declining stock situation, herring have been reported to exhibit changes in their prespawning behaviour (Murphy 1977). In the present paper, we examined the hypothesis that Atlantic herring in the northern North Sea, in July (i.e., 2 to 3 mo prior to their spawning) are likely to be associated with suitable potential spawning grounds, despite substantial changes in the stock level and age structure of the population. The objective was to establish quantitative relationships between the spatial distribution of prespawning herring abundance and biotic and environmental factors over a wide geographical area, the northern North Sea, using acoustic backscatter data for information about fish abundance, seabed substrate and bottom depth. Fisheries acoustics datasets allow a mesoscale view of the spatial structure of the population to be obtained. The simultaneous collection of a wide range of ancillary variables, biotic (e.g., zooplankton) and abiotic (e.g., depth, seabed substrate). during the acoustic surveys enables an understanding of the relationship between population distribution and the ocean environment. 


\section{MATERIALS AND METHODS}

Data collection. Fish abundance and water depth data: Herring data were collected during the ICES cooperative acoustic surveys in the northern North Sea (Orkney/Shetland area), ICES div. IVa (1992, 1994, 1995). The procedures for herring acoustic data acquisition have been described in detail in MacLennan \& Simmonds (1992) and Anon (1994). Water depth was collected routinely as part of the acoustic data during these surveys.

Zooplankton data: Zooplankton samples were taken at trawl stations and opportunistically throughout the 1995 survey. Vertical samples were taken using a standard plankton net $(250 \mu \mathrm{m}$ mesh size, $1 \mathrm{~m}$ diameter $)$ from the upper $60 \mathrm{~m}$ of the water column. Samples were fixed and preserved in an excess borax-buffered $4 \%$ formaldehyde solution. Back in the laboratory the samples were sorted. Species were identified, counted and converted to dry weights. Numerical densities of species (including copepods) were converted to dry weight using a standard set of stage length and dry weight data (Hay 1995). These were then converted to dry weight biomass $\mathrm{m}^{-3}\left(\mathrm{mg} \mathrm{m}^{-3}\right)$ for the top $60 \mathrm{~m}$ of the water column. For purposes of the present study only the small crustacean category was used. This category was dominated ( $99 \%$ ) by calanoid copepods (mainly Calanus finmarchicus) at various stages of development. C. finmarchicus is the main prey of herring (Parrish \& Saville 1965) and comprises more than $70 \%$ of the zooplankton in the northern North Sea during June-July (Fransz et al. 1991).

Seabed substrate data: Seabed substrate data were collected using the RoxAnn system for the surveys in 1992, 1994 and 1995. RoxAnn provides 2 descriptors of the substrate: E1 representing bottom roughness and E2 representing bottom hardness. In general, the resolution of the system in any one situation is restricted to around 6 substrate types. During the surveys the RoxAnn system was set to gather data at $15 \mathrm{~s}$ intervals. Data were displayed and stored on an Apple Mac running MacSea G.I.S. software. More specific details of the theoretical basis of RoxAnn are given in Chivers et al. (1990); a field evaluation of RoxAnn is presented in Schlagintweit (1993).

Exploratory data analysis (EDA). Herring abundance (integrated echo intensity) and water-depth data were available at 15 min intervals (every $2.5 \mathrm{n}$ miles) for all the surveys. Zooplankton biomass was available only at plankton point stations. The local regression model, LOESS, was used first to model zooplankton biomass as a function of latitude and longitude and then, in a predictive mode, to interpolate onto each abundance data location. RoxAnn data were screened for invalid data prior to further processing; then, to allow direct correspondence to the herring acoustic data, mean $\mathrm{E} 1$ and $\mathrm{E} 2$ values were calculated for each $15 \mathrm{~min}$ interval.

Data analysis. Generalized Additive Models (GAMs; Hastie \& Tibshirani 1990, Swartzman et al. 1992) were used to model trends in herring abundance distribution (for 1992, 1994, 1995) as functions of seabed substrate, bottom depth and zooplankton biomass, with the main aim being to draw inferences on the mechanisms that give rise to the distribution of herring. To begin with, we applied GAMs to each year's dataset separately. Then, since the coverage of the 3 surveys was the same, it was possible to combine the 3 years' data in one analysis and test for a temporal (i.e., year) effect on herring abundance. In the present study, the available covariates that were examined were: RoxAnn E1 seabed roughness, RoxAnn E2 - seabed hardness, water depth, zooplankton biomass (1995 only).

All available variables and their first-order interactions were initially included in the model. Seabed substrate roughness and hardness were found to be correlated; however their relationship changes over space, and therefore they cannot be seen as surrogates. Because of this and because there was no a priori information for which of the 2 was more important for herring, it was decided to include both covariates in the model. For both approaches, an identity link function and a gaussian error distribution was found to be adequate for the data modelled here. The scatterplot smoother used here to estimate the functions in GAMs was a cubic spline smoother, s (Hamming 1973). A detailed description of the GAM methodology, as it was applied in the present study, is given in Swartzman et al. (1992) and in Maravelias (1997), and we refer the reader to these studies for more information.

\section{RESULTS}

Contour plots of the seabed roughness, hardness, bottom depth and herring density for the years 1992, 1994 and 1995 are given in Figs. 2 to 4 respectively. The effect of each of the explanatory variables included in the GAMs can be best understood by examining the fitted contribution of each variable to total herring abundance plotted against the value of the variable. The $95 \%$ confidence intervals are also plotted around the best fitting smooths for the main effects. Interaction effects are shown as perspective plots without error bounds. The $y$-axis reflects the relative importance of each covariate of the model; for the interaction effects this is presented on the $z$-axis. Finally, the $x$-axis for the single covariate effect plots includes a so-called 'rug', which shows the density of points for each covariate included in the model. 
The results of the best fitting GAM smooths for significant main effects and interactions on herring abundance are presented in Figs. $5 \& 6$ for the first analytical approach, i.e., all data included. It needs to be emphasized that the effect of each variable shown in
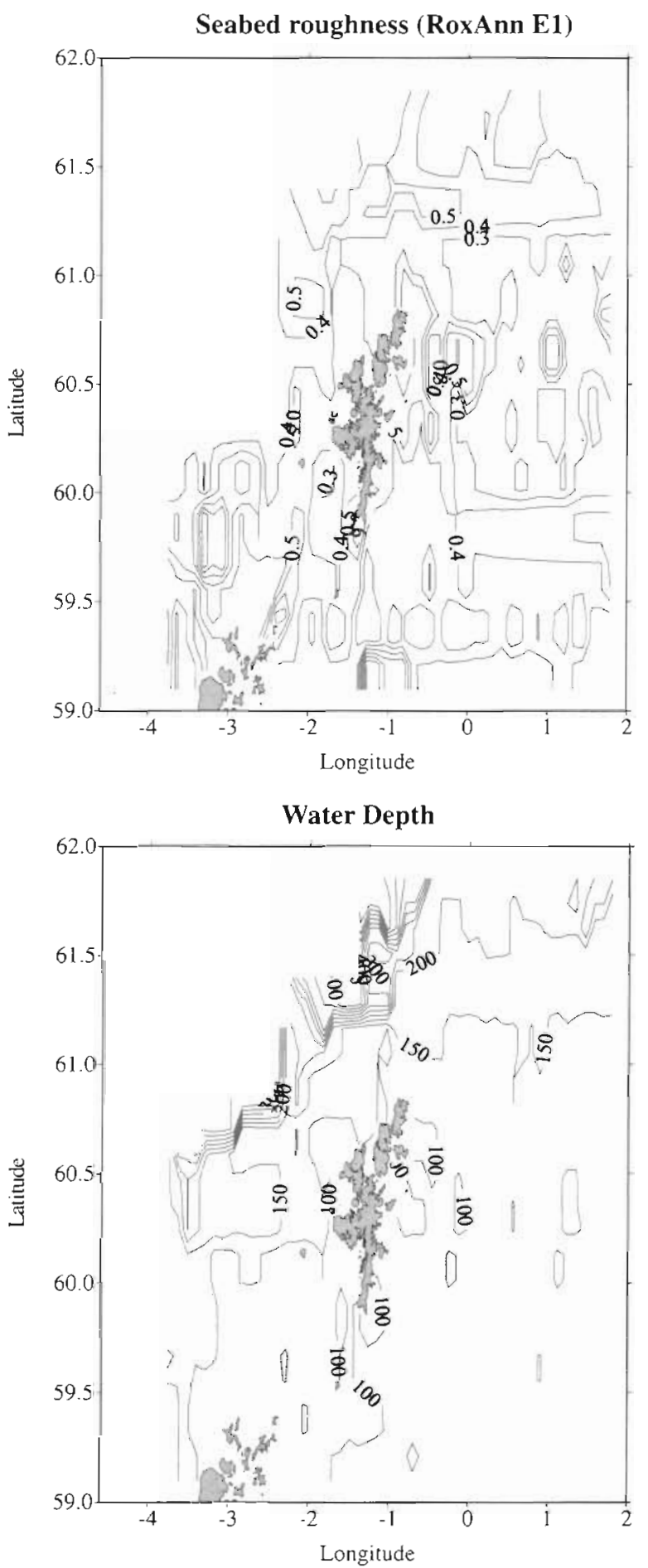

the above figures is the conditional effect, that is, the effect that this variable has, given that the other variables are included in the model. In Table 1 the significance values ( $p$-levels) of GAM covariates for all years are given.
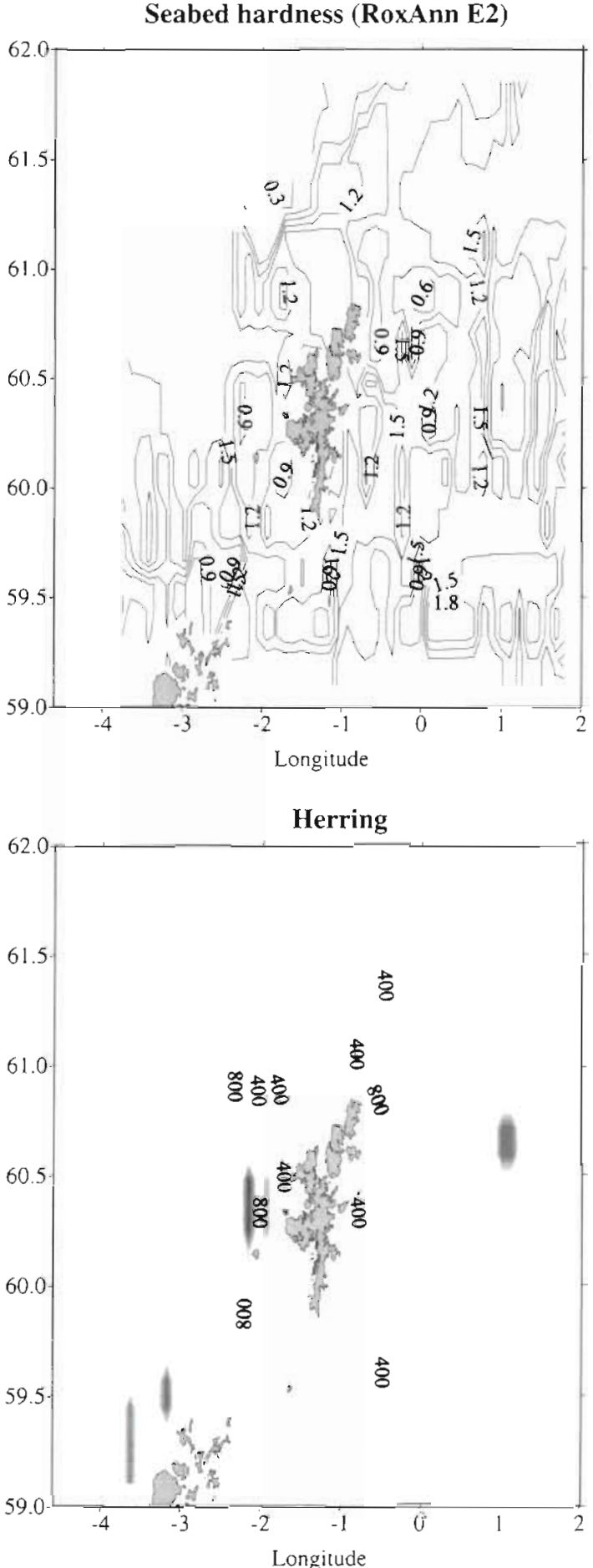

Fig. 2. Contour plots of seabed roughness (E1), seabed hardness (E2), water depth and observed herring data for 1992 


\section{Full raw data modelling}

First, all the data were examined without any distinction. The total herring abundance through the water column was regressed against seabed roughness, seabed hardness, bottom depth and zooplankton biomass. Herring abundance for 1995 was also simultaneously regressed against the interaction of zooplankton with bottom depth.

Results from the GAMs applied in all years were similar. The explanatory covariates were significant in all years (Table 1). The main effects of the common ex-
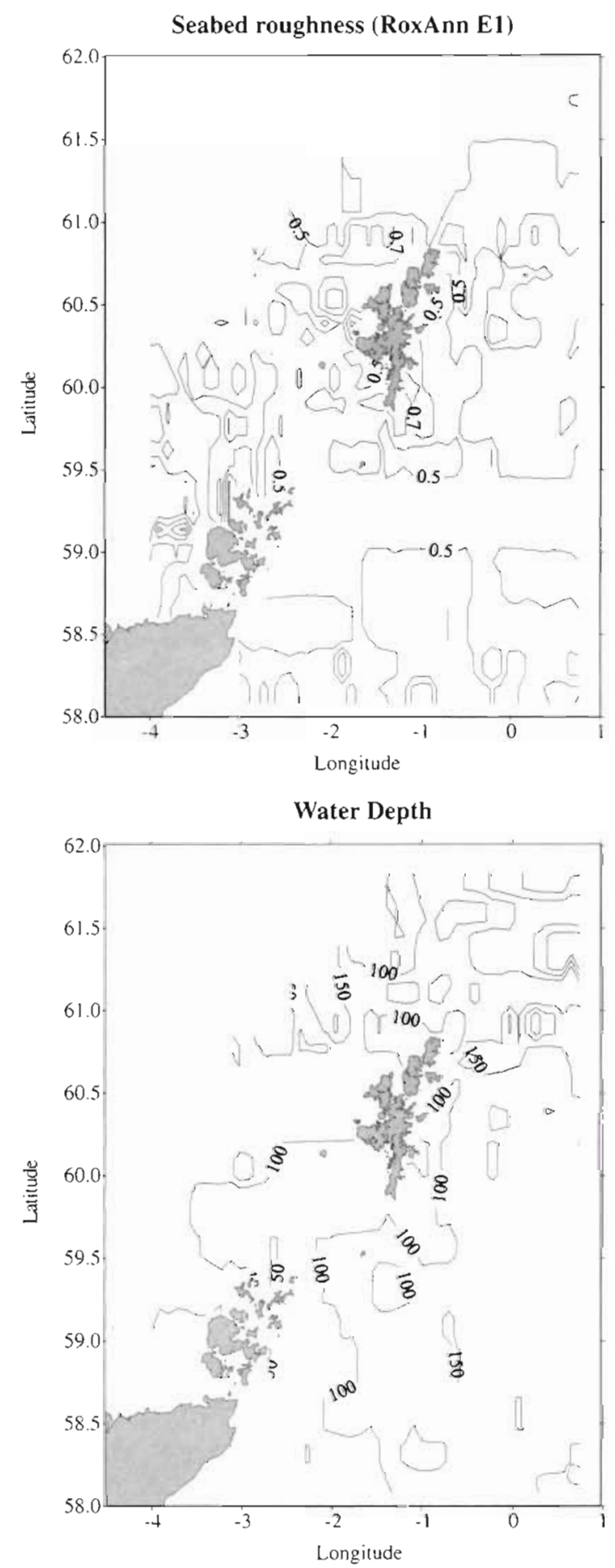

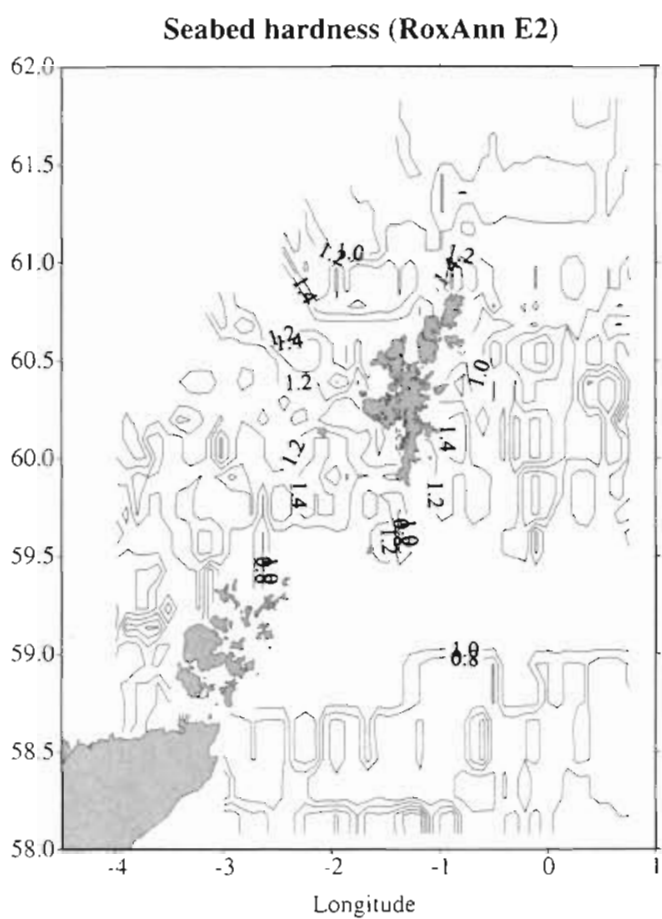

Herring

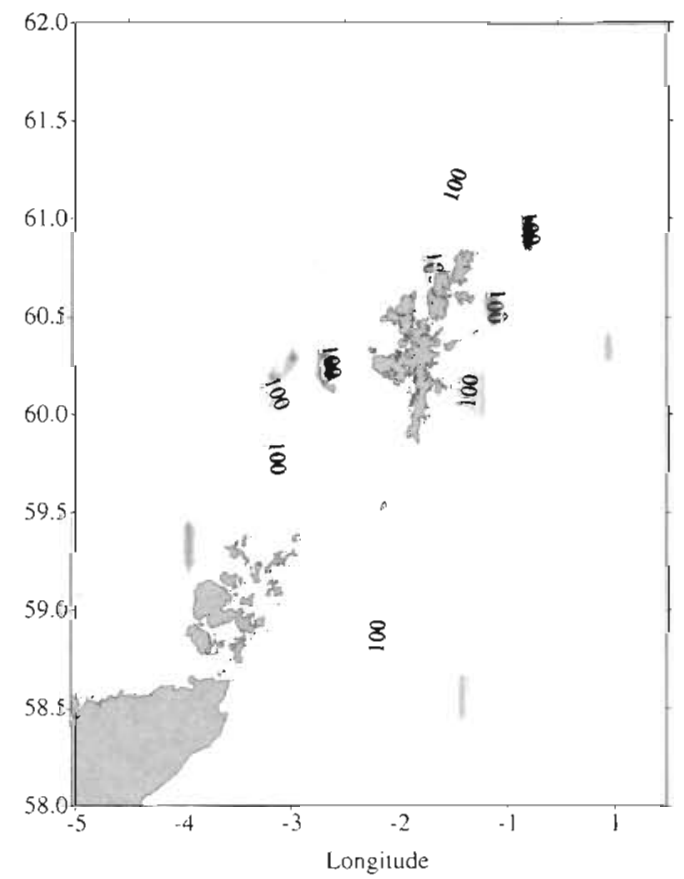

Fig. 3. Contour plots of seabed roughness (E1), seabed hardness (E2), water depth and observed herring data for 1994 
planatory variables were more significant for 1992 than 1994/95. For 1995 the zooplankton biomass and its interaction with bottom depth were highly significant.

The best fitting smooths of the covariates on herring abundances can be seen in Figs. 5 \& 6. The main
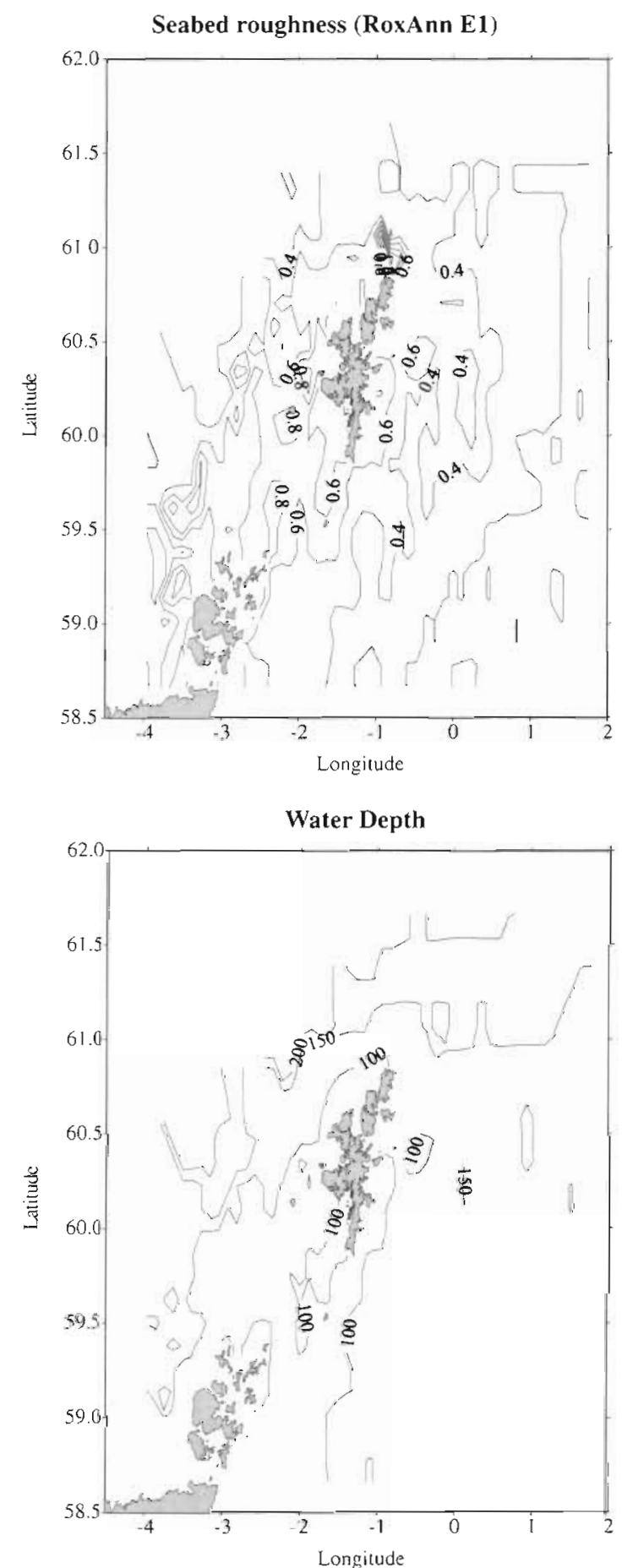

effects of seabed roughness, hardness and depth showed little interannual change. Interactive effects in all 3 years were non-significant. The best fitting smooths of the explanatory covariates revealed similar patterns for the same ranges of values between years,
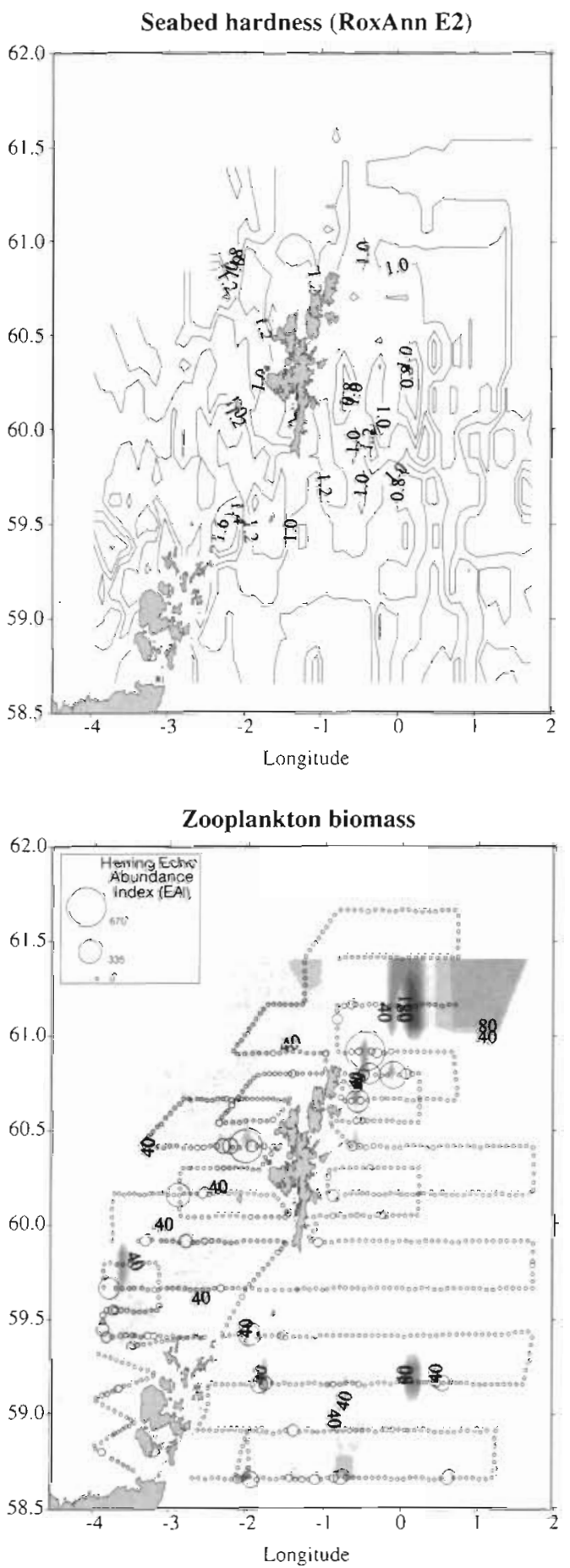

Fig. 4. Contour plots of seabed roughness (E1), seabed hardness (E2) and water depth for 1995. The zooplankton biomass is given with a proportional representation of the herring data (bottom right). Radius of circles is proportional to herring EAI 
thus suggesting that the relationship of herring with these variables was rather constant and characteristic.

Fish abundances were greatest for seabed roughness values around 0.6 Volts (V) in all years. Average herring abundance increased with increasing seabed hardness values and exhibited its maximum effect for hardness values around $0.9 \mathrm{~V}$. Based on the Marine Laboratory's grab sampling database and ground truthing, hardness values lower than $0.6 \mathrm{~V}$ were known to represent soft sediment types i.e., mud and silt; hardness values (E2) higher than $0.6 \mathrm{~V}$ and lower
Table 1. Significance values ( $p$-levels) for all GAM covariates and their interactions. Level of significance was set to 0.05 . Not available covariates for 1992 and 1994 are denoted as na

\begin{tabular}{|lccc|}
\hline Covariate & 1992 & 1994 & 1995 \\
\hline Seabed roughness & 0.001 & 0.03 & 0.003 \\
Seabed hardness & 0.001 & 0.001 & 0.001 \\
Bottom depth & 0.002 & 0.003 & 0.002 \\
Zooplankton biomass & na & na & 0.001 \\
Bottom depth - & na & na & 0.001 \\
zooplankton biomass interaction & & \\
\cline { 2 - 4 } & & & \\
\end{tabular}

\section{Full data}
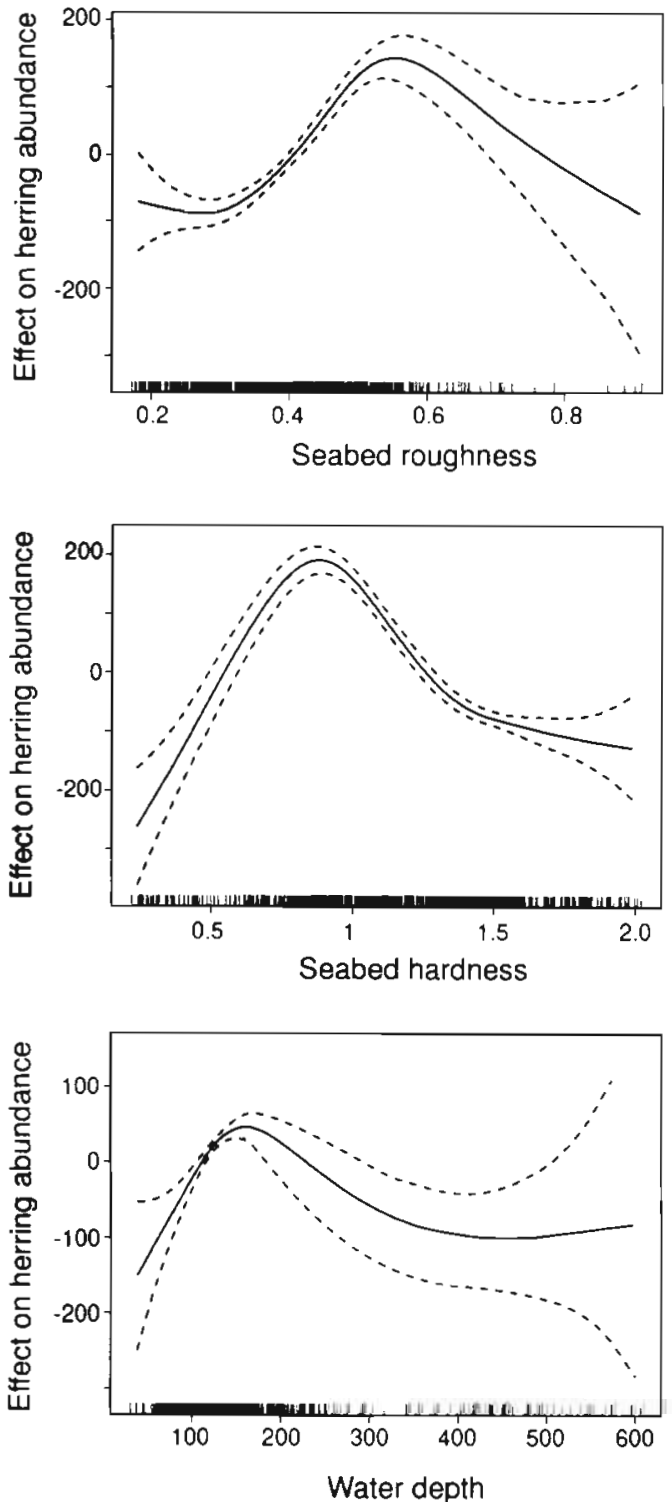

1994 Full data
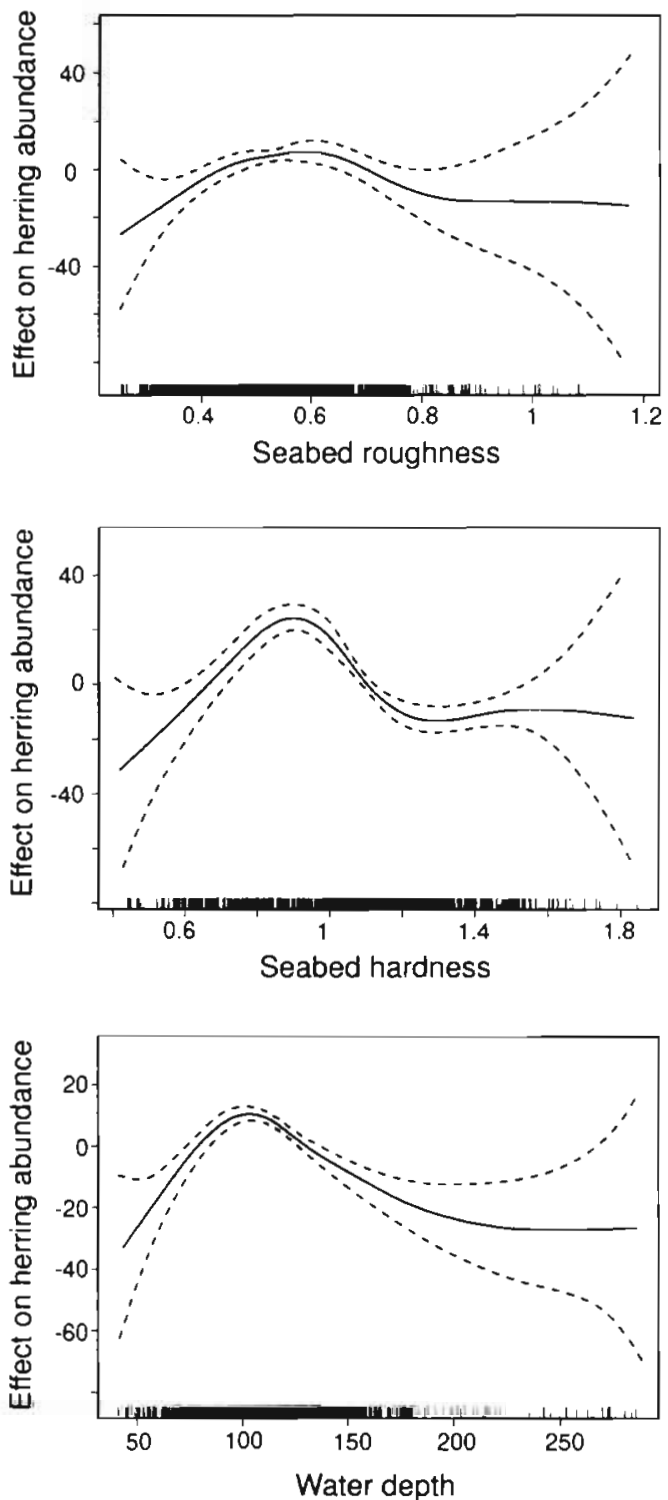

Fig. 5. Results of GAM regression for 1992 (left) and 1994 (right) herring abundance as a function of seabed roughness (RoxAmn E1), seabed hardness (RoxAnn E2) and water depth. Dashed lines: 1 SE boundary around the covariate effects 
than $1.2 \mathrm{~V}$ were characteristic of sand and gravel seabed grounds; E2 values greater than $1.2 \mathrm{~V}$ and smaller than $1.5 \mathrm{~V}$ represented stone covered seabeds, whereas E2 values greater than $1.5 \mathrm{~V}$ reflected rocky seabed substrate. Average herring abundance was high for bottom depths 110-250 $\mathrm{m}$ in 1992, 75-140 m in 1994 and $90-170 \mathrm{~m}$ in 1995. In deeper waters average herring abundance was lower.

For 1995, there was an increase in average herring abundance with increasing zooplankton biomass.
More precisely, high herring abundances were associated with zooplankton biomass values greater than $40 \mathrm{mg} \mathrm{m}^{-3}$. The higher the zooplankton biomass, the higher the herring abundance, up to a zooplankton biomass value of $110 \mathrm{mg} \mathrm{m}^{-3}$, beyond which herring abundance decreased.

In 1995 there was a highly significant interaction of bottom depth with zooplankton. Areas with low zooplankton biomass regardless of bottom depth were associated with low herring abundances. Average her-

\section{Full data}
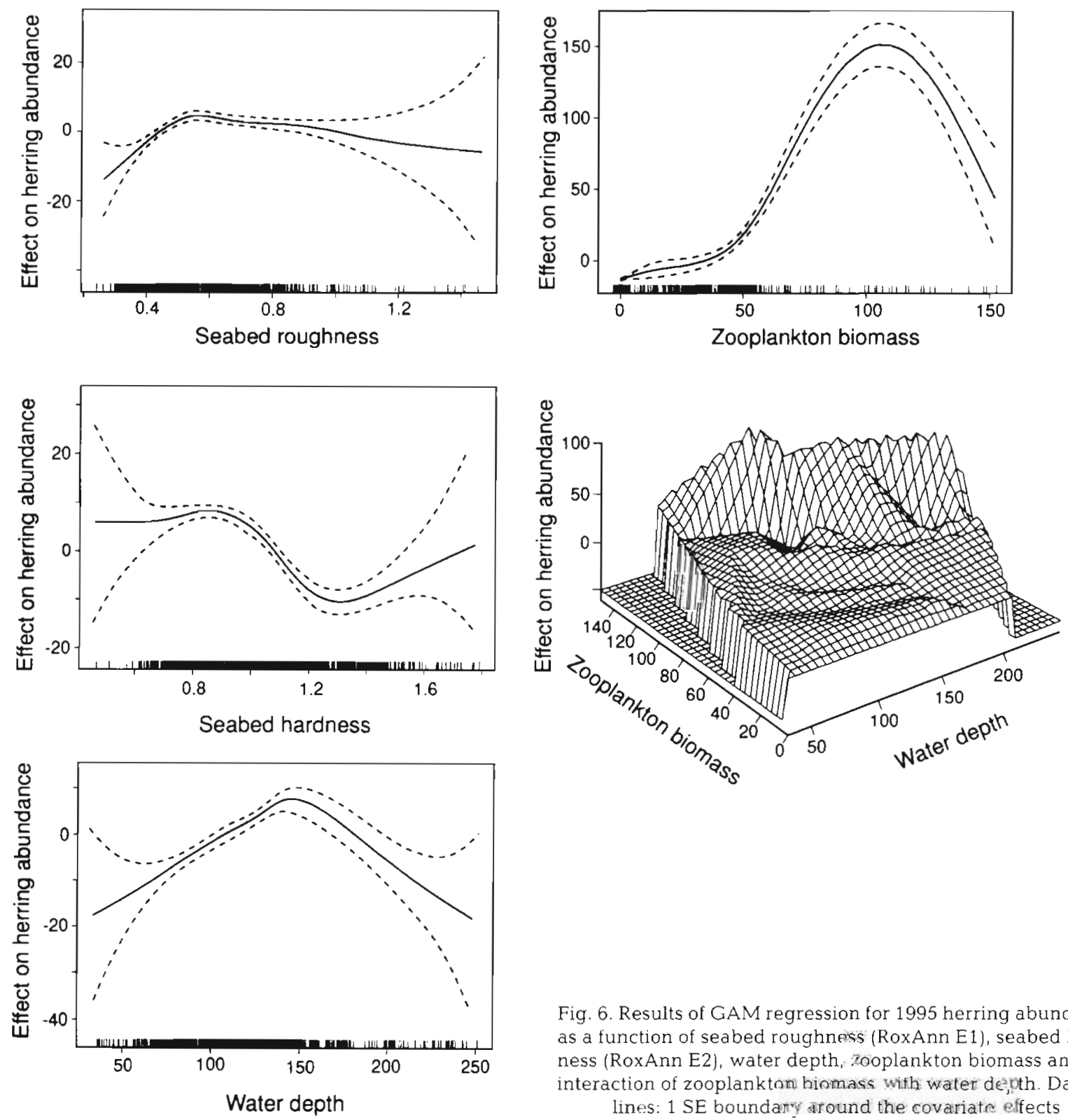

Fig. 6. Results of GAM regression for 1995 herring abundance as a function of seabed roughness (RoxAnn E1), seabed hardness (RoxAnn E2), water depth, zooplankton biomass and the interaction of zooplankton biomass with water depth. Dashed lines: 1 SE boundary around the covariate effects 
ring abundance was the highest at areas with zooplankton rich waters of $140 \mathrm{~m}$ depth. At bottom depths greater than $150 \mathrm{~m}$ herring abundance increased with increasing zooplankton biomass up to $120 \mathrm{mg} \mathrm{m}^{-3}$ (approximately). Furthermore, the effect of the zooplankton biomass on herring abundance was greater in shallower waters $(<140 \mathrm{~m})$.

\section{Temporal effects}

In Fig. 7 results of the GAM with a year-effect are given. By including a year-effect we were able to combine all years into the same analysis and hence to compare the GAM results of individual years with this combined analysis. All covariates included in the model were found to be highly significant. For the entire 3 yr period examined, the herring abundance was, on average, greatest in shallow $(70$ to $150 \mathrm{~m})$ areas with seabed substrate gravel and/or sand. A direct comparison of the yearly GAM smooths with the multiyear GAM smooths revealed that the spatial distribution of herring is subject to the same environmental influences each year. Moreover, the multiyear GAM analysis also indicated a significant year-effect on herring abundance. Although 1993 data were lacking, an apparent decrease on herring abundance was observed. Herring abundance was high in 1992 but gradually decreased through 1994 and 1995.

\section{DISCUSSION}

Pre-spawning herring in the northern North Sea exhibited a consistent multiyear relationship with seabed substrate and bathymetry. The sediment type, bottom depth and the prey abundance appeared to be key determinants of distribution during 1992, 1994 and 1995. Explanatory factors with the strongest associations were: seabed hardness (E2), bottom depth and zooplankton biomass. Seabed roughness (E1) and the interaction of bottom depth with zooplankton biomass (1995 only) were also found to be significant. Based on the results of the current analysis, and on the E1 and E2 preferenda found, it can be concluded that herring showed a distinct preference for a gravel/sand type of seabed.

The present findings confirm the conclusions of Blaxter (1990), Haegele \& Schweigert (1985) and Parrish \& Saville (1965), showing herring preference for spawning on high energy gravel substrates (i.e., gravel seabeds in areas of high water movement, e.g., tidal currents). Additionally, Haegele \& Schweigert (1985) suggested that the fish would aggregate near their spawning grounds for some time prior to spawning.
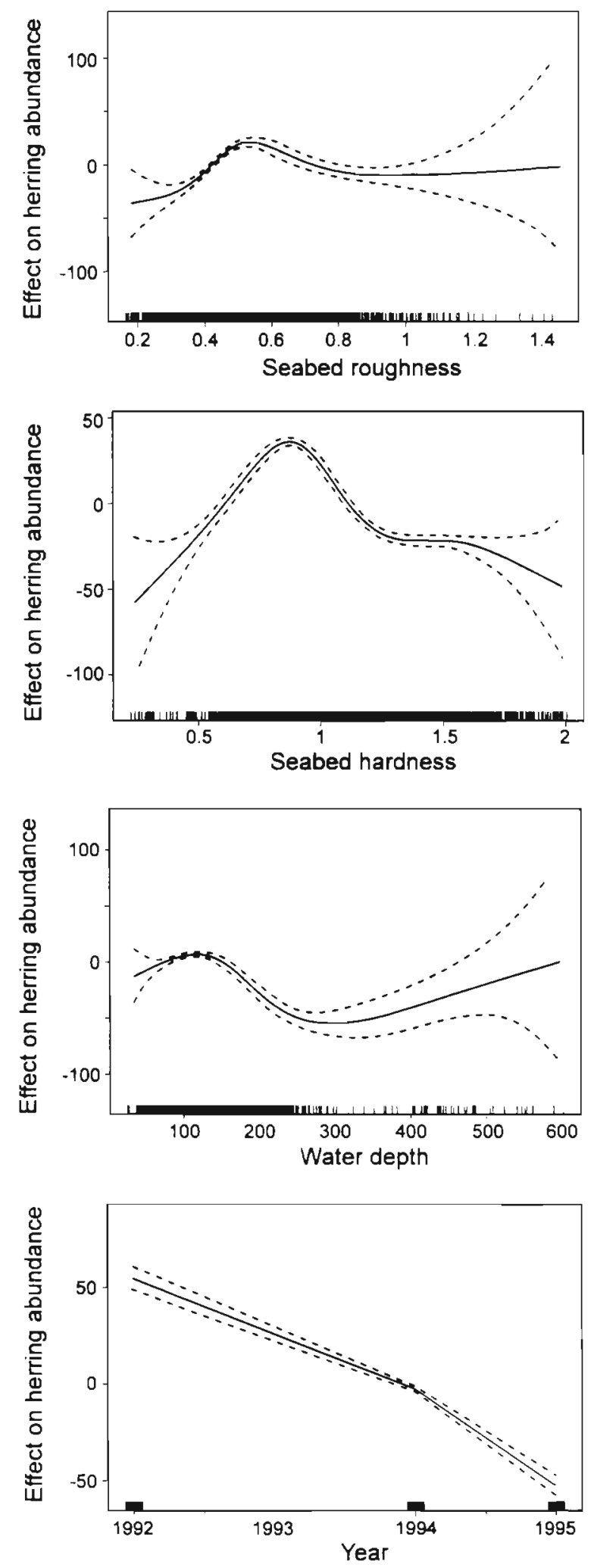

Fig. 7. Multiyear GAM regression plots of the best fitting smooths for the entire sampling period 1992-95 as a function of seabed roughness (RoxAnn E1), seabed hardness (RoxAnn E2) and water depth. Dashed lines: $1 \mathrm{SE}$ boundary around the covariate effects 
Acoustic surveys in this part of the North Sea show relatively consistent distributions in recent years (Bailey et al. 1998). In general, the distributions show the fish to be in the area where spawning is expected to take place (Corten 1988, 1990). This would suggest that, while these herring are a migratory stock, they are probably not actively migrating at this time. This stability is also confirmed by commercial catch data (Corten \& van de Kamp 1992). From the present observations of preference for gravel substrates it seems likely that by July the herring have largely completed their pre-spawning migration and are beginning to aggregate close to potential spawning grounds. While not yet spawning at this time, the herring still show a preference for suitable spawning substrates.

Bottom depth was found to have both a direct main effect and an interactive effect (with zooplankton biomass) on herring abundance. Waters with seabed deeper than $250 \mathrm{~m}$ were always associated with low herring densities or no herring at all. In all 3 years the highest average herring abundances were found in waters with seabed depth less than $170 \mathrm{~m}$. These findings are consistent with previous observations, both for these surveys (Simmonds et al. 1993, 1995, 1996, Reid et al. 1993. Maravelias 1997) and also for other areas (Blaxter \& Holliday 1963, Blaxter \& Hunter 1982). Since herring prefer to spawn in high energy gravel areas, this constraint is likely to restrict acceptable spawning areas to relatively shallow waters as tidal flow is likely to be reduced in the deeper waters. Herring spawn in very shallow waters in some areas, e.g., in the Baltic (Korolev et al. 1993) and in the Clyde area of Scotland (Rankine 1986). In these cases the areas are relatively sheltered from storms etc., although losses due to storms in the Clyde have been recorded (J. Morrison, FRS Marine Laboratory, Aberdeen, pers. comm.). In the much more exposed waters of the North Sea it is likely that the autumn spawning herring would lay their eggs in deeper waters to avoid such losses.

Herring tended to be found in greatest abundance at the edges of higher zooplankton density areas in the present study. In 1995 the zooplankton biomass had a significant effect on pre-spawning herring distributional abundance both directly, as a main effect, and indirectly, through its interactive effect with water column depth. Studies on Atlanto-Scandian herring (Jakobsson 1978) showed a very similar pattern. Two possible explanations can be advanced for this. One is that the herring are effectively grazing down the patches of zooplankton, and so tend to be found on the edges rather than the centres of patches. Alternatively, zooplankton production is probably greatest in or close to frontal zones (Laevastu 1993, Lali \& Parsons 1993). and herring have been shown to prefer areas adjacent to such areas (Maravelias \& Reid 1995, 1997. Mara- velias et al. 2000). The combined effect would be to place herring close to, but slightly displaced from, the maximum zooplankton abundance.

One significant finding of this analysis is the temporal stability of the relationships between herring abundance and the seabed substrate and bathymetry. It is of particular note that this stability occurred over a period of substantial stock reduction (Anon 1996, ICES 1997). Results from the multiyear GAM analysis confirmed this reduction further, and evidently serve as an additional validation of the findings of the present study. The observed year-to-year differences in herring abundance in the northern North Sea, during 1992-95, were not environmentally driven (Maravelias 1997).

It is more than likely that, in the northern North Sea, the bathymetry and substrate will be important in the future pattern of the stock distribution. Two to three months (July) prior to their spawning period, adult herring exhibited strong attachment to the particular grounds on which they later spawned (i.e., SeptemberOctober). The study has demonstrated the utility of acoustic surveys and seabed classification systems such as RoxAnn to examine the underlying factors which control herring distribution in more detail than has previously been possible. The link between zooplankton (small crustacean) distribution, bathymetry and herring distribution is also important, and it is hoped that the collection of such data along with acoustic survey data in the future will clarify these relationships further.

Acknowledgements. We would like to acknowledge the financial support of the European Commission FAIR Programme (Contract: ERB GT 96 1116) to C.D.M. and the support and advice of our colleagues at the Marine Laboratory, particularly Steve Hay and Eric Armstrong. Ad Corten and Monty Priede provided useful comments on an earlier draft.

\section{LITERATURE CITED}

Anon (1994) Report of the planning group for herring surveys. ICES CM 1994/H:3

Anon (1996) Herring Assessment Working Group for the area south of $62 \mathrm{~N}$. ICES CM 1996/A:10

Bailey MC, Maravelias CD, Simmonds EJ (1998) Changes in the spatial distribution of autumn spawning herring ( $\mathrm{Clu}$ pea harengus L.) derived from annual acoustic surveys during the period 1984-1996. ICES J Mar Sci 55:545-555

Bainbridge V, Forsyth DCT (1972) An ecological survey of a Scottish herring fishery. Part V: The plankton in the Northwestern North Sea in relation to the physical environment and the distribution of herring. Bull Mar Ecol 8:21-52

Blaxter JHS (1990) The herring. Biologist 37(1):27-31

Blaxter JHS, Holliday FGT (1963) The behaviour and physiology of herring and other clupeoids. Adv Mar Biol 1: 261-393

Blaxter JHS, Hunter JR (1982) The biology of the clupeoid fishes. Adv Mar Biol 20:1-223 
Chivers RC, Emerson N, Burns, D (1990) New acoustic processing for underway surveying. Hydrobiol J 56:9-17

Corten A, van de Kamp G (1992) Natural changes in pelagic fish stocks of the North Sea in the 1980s. ICES Mar Sci Symp 195:402-417

Corten A (1988) Shift in herring spawning areas in the Northwestern North Sea in relation to environmental changes. ICES CM 1988/H:22

Corten A (1990) Long-term trends in pelagic fish stocks of the North Sea and adjacent waters and their possible connection to hydrographic changes. Neth J Sea Res 25(1/2): $227-235$

Cushing DH (1955) Production and a pelagic fishery. Fish Invest Lond Ser 2, 18 (7)

Fransz HG, Colebrook JM, Gamble JC, Krause M (1991) The zooplankton of the North Sea. Neth J Sea Res 28:1-52

Haegele CW, Schweigert JF (1985) Distribution and characteristics of herring spawning grounds and description of spawning behaviour. Can J Fish Aquat Sci 42:39-42

Hamming RW (1973) Numerical methods for scientists and engineers. McGraw-Hill, New York

Hardy AC (1936) The ecological relations between the herring and the plankton investigated with the plankton indicator. J Mar Biol Assoc UK 21:147-178

Hastie T, Tibshirani R (1990) Generalized additive models. Chapman and Hall, London

Hay S (1995) Egg production and secondary production of common North Sea copepods: field estimates with regional and seasonal comparisons. ICES J Mar Sci 52: 315-327

ICES (1997) Report of the Herring Assessment Working Group for the Area South of $62^{\circ} \mathrm{N}(1 / 2)$. ICES CM 1997/Assess:8

Jakobsson J (1978) The north Icelandic herring fishery and environmental conditions, 1960-1968. In: Symposium on the biological basis of pelagic fish stock management. Aberdeen, No. 30

Korolev A, Kuznetsova T, Drozdetzsky V (1993) Features of the Baltic herring's spawning gounds in the eastern Baltic. ICES CM 1993/J:23

Laevestu $T$ (1993) Marine climate, weather and fisheries Fishing News Books, London

Lali CM, Parsons TR (1993) Biological oceanography: an introduction. Pergamon Press, Oxford.

MacLennan DN, Simmonds EJ (1992) Fisheries acoustics. Chapman Hall, London

Editorial responsibility: Otto Kinne (Editor), Oldendorf/Luhe, Germany
Mann KH (1993) Physical oceanography, food chains and fish stocks, a review. ICES J Mar Sci 50:105-119

Maravelias CD (1997) North Sea herring (Clupea harengus, L.) distribution in relation to environment: analysis of acoustic survey data (1992-1995). PhD thesis, University of Aberdeen

Maravelias CD, Reid DG (1995) Relationship between herring (Clupea harengus L.) distribution and sea surface salinity and temperature in the northern North Sea. Sci Mar 59: $427-438$

Maravelias CD, Reid DG (1997) Identifying the effects of oceanographic features and zooplankton on prespawning herring abundance using generalized additive models. Mar Ecol Prog Ser 147:1-9

Maravelias CD, Reid DG, Swartzman G (2000) Modelling spatio-temporal effects of environment on Atlantic herring using GAMs. Environ Biol Fish (in press)

Murphy GI (1977) Clupeoids. In: Gulland JA (ed) Fish population dynamics. John Wiley, London, p 283-308

Parrish BB, Saville A (1965) The biology of the Northeast Atlantic Herring populations. Oceanogr Mar Biol Annu Rev 3:323-373

Rankine PW (1986) Herring spawning grounds around the Scottish coast. ICES CM 1986/H:15

Reid DG, Williams D, Gambang A, Simmonds J (1993) Distribution of North Sea herring and their relationship to the environment. ICES CM 1993/H:23

Schlagintweit GEO (1993) Real time acoustic bottom classification for hydrography: a field evaluation of RoxAnn. Report to the Canadian Hydrographic Service, Department of Fisheries and Oceans, Ottawa, Ontario

Simmonds EJ, Dommasnes A, Aglen A, Corten A, Reid DG (1993) 1992 ICES coordinated acoustic survey of ICES divisions IVa, IVb \& VIa. ICES CM 1993/H:11

Simmonds EJ, Toresen R, Corten A, Pedersen J, Reid DG, Fernandes PG, Hammer C (1995) 1994 ICES coordinated acoustic survey of ICES divisions IVa, IVb \& VIa. ICES CM 1995/H:18

Simmonds EJ, Toresen R, Corten A, Pedersen J, Reid DG, Fernandes PG, Hammer C (1996) 1995 ICES coordinated acoustic survey of ICES divisions IVa, IVb \& VIa. ICES CM 1996/H:8

Swartzman G, Huang C, Kaluzny S (1992) Spatial analysis of Bering Sea groundfish survey data using generalized additive models. Can J Fish Aquat Sci 49:1366-1378

Submitted: May 20, 1999; Accepted: October 21, 1999

Proofs received from author(s): March 10,2000 